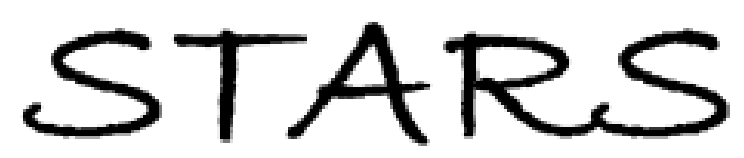

University of Central Florida

STARS

Faculty Scholarship and Creative Works

6-23-2013

\title{
The Relevance of Cultural Tourism as the Next Frontier for Small Island Destinations
}

Robertico R. Croes

University of Central Florida, robertico.croes@ucf.edu

Kelly J. Semrad

University of Central Florida, Kelly.Semrad@ucf.edu

Part of the Hospitality Administration and Management Commons, and the Tourism and Travel Commons

Find similar works at: https://stars.library.ucf.edu/ucfscholar

University of Central Florida Libraries http://library.ucf.edu

This Paper is brought to you for free and open access by STARS. It has been accepted for inclusion in Faculty Scholarship and Creative Works by an authorized administrator of STARS. For more information, please contact STARS@ucf.edu.

\section{Original Citation}

Croes, R. and Semrad, K. (2013). The relevance of cultural tourism as the next frontier for small island destinations. Journal of Hospitality and Tourism Research, 39(4), 469-491.

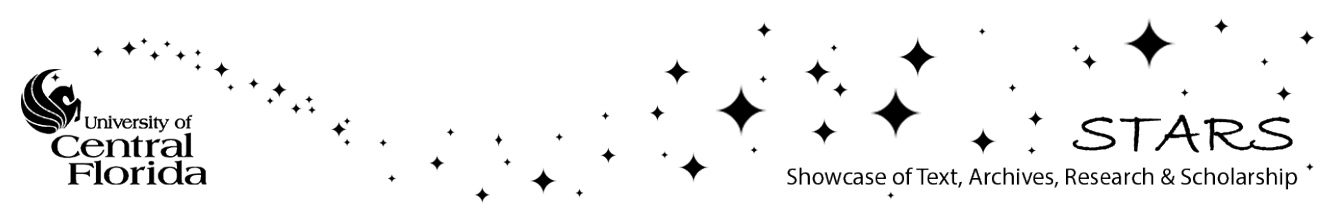


Croes, R. \& Semrad, K. (2015). The relevance of cultural tourism as the next frontier for small island destinations. Journal of Hospitality and Tourism Research, 39(4), 469-491.

\author{
Robertico Croes \\ Rosen College of Hospitality Management \\ University of Central Florida
}

and

Kelly J. Semrad

Eric Friedheim Tourism Institute

University of Florida

\begin{abstract}
The purpose of this study is to apply the cultural tourism typology that was forwarded by McKercher (2002) and to estimate the economic relevance of cultural tourism to the context of a small island destination tourist market. The application of this cultural tourism typology is used in order to determine if those typologies may be used to segment tourists thereby allowing researchers to determine the economic impact of different cultural tourist segments to tourism destinations' economies. The study draws attention to some of the foundational issues that researchers face when attempting to quantify the economic impact of cultural tourists. The results of the study indicate that the McKercher's typology may provide more refined results when incorporating the purpose of a trip; and, that cultural tourists may be a lucrative market for destinations to pursue given the results of an economic Input-Output Model.
\end{abstract}

Keywords: cultural tourism, economic impact, small island destination, Aruba

\title{
INTRODUCTION
}

The purpose of this study is to apply the cultural tourism typology that was forwarded by McKercher (2002) and to estimate the economic relevance of cultural tourism to the context of a small island destination tourist market. The application of this cultural tourism typology is used in order to determine if the cultural tourism typologies may be used to segment tourists thereby allowing researchers to determine the economic impact of different cultural tourist segments to tourism destinations' economies. McKercher's (2002) cultural tourism typology was based on the interface between centrality of cultural tourism as a trip motive and the depths of cultural tourists' experiences. Small island destinations are searching for ways to reinvent themselves in their quest for enhancing their competitiveness through tourism specialization thereby ensuring increasing returns (Croes, 2011).

A pertinent consideration is whether embracing cultural tourism could enhance the overall value of the tourism product in a small island destination. The study calls for the critical attention regarding the major challenges that researchers may encounter when attempting to 
empirically assess the overall economic value of cultural tourists to a destination. The foundational challenge in analyzing cultural tourism consumption is the vast scope of meanings implied by the concept culture. This foundational challenge gives way to then an issue regarding efficacy of accurate measurement and consequently units of analysis that may be considered in the empirical assessment of the value of cultural tourism.

A cursory glance at the history of tourism consumption indicates that the emphasis on usage has shifted over time, away from the process of cultivation, towards a focus on process and product (Pizam \& Croes, 2007). The former refers to codes of conduct embedded in specific social groups (a kind of way of life) while the latter refers to activities or practices with specific meanings attached. The latter two meanings of culture seem to be the consequence of the changing nature of demand in tourism. This study focuses on culture as product and its relationship to the pattern of tourism consumption as its object of analysis. The study claims that cultural tourism could encourage reinvention strategies aiming to enhance the destination competitiveness of a small island destination. The study investigates the empirical relationship between tourism and culture in the context of Aruba; and, measures the economic impact of that relationship. The study addresses two related research questions:

Q1: What are the different segments that comprise the cultural market in Aruba? Q2: What is the economic contribution of cultural tourism in the case of Aruba?

In order to assess the research questions the study entertains two central arguments. First, it argues that cultural tourism should be empirically assessed and its economic value estimated in order to determine its relevance in tourism development. Second, cultural tourism could play a significant role in ensuring incremental returns through tourism specialization. Understanding the process of cultural tourism could unleash new opportunities for product development, new markets and new wealth thereby underscoring the main premise of endogenous growth theories (Romer, 1994). This study is one of the first investigations that assess cultural tourism empirically as it applies to a small island destination.

\section{Literature Review}

Cultural tourism encompasses cultural activities and experiences that are highly appealing and enriching to tourists. The literature seems to indicate that cultural tourism is a new growth area of tourism demand and that it may aid in seasonal and geographic spread of tourism thereby increasing revenues (Cole \& Razak, 2003; Richards, 1994; Richards \& Wilson, 2007). Thus, destinations have increased the promotion of cultural and heritage assets for tourism consumption. And yet, according to the literature, defining cultural tourism has not been easy (McKercher, 2002). Definition of this construct has proven difficult because there are almost as many definitions or variations of definitions as there are cultural tourists. The lack of a definition has hampered an understanding of this construct and how policy makers to improve and expand tourism as an experience may use it. Literature places cultural tourism within a broader framework of tourism and recognizes it as a type of special interest tourism, where culture forms the basis of either attracting or motivating people to travel.

The World Tourism Organization (1985) provided two definitions of cultural tourism. The 
narrower definition includes "movements of persons essentially for cultural motivations such as study tours, performing arts and cultural tours, travel to festivals and other events, visits to sites and monuments, travel to study nature, folklore or art, and pilgrimages." The wider definition includes: "all movements of persons... because they satisfy the human need for diversity, tending to raise the cultural level of the individual and giving rise to new knowledge, experience and encounters." These two definitions may seem rather tautological in nature, but they capture two essential components of cultural tourism: i.e., motivation and activities. Yet, both definitions lack a sense of purpose. If you are motivated and engaged in cultural activities, it still does not respond to another important element of traveling, which is purpose. The level of engagement and purpose for travel constitutes the most serious missing elements of these definitions thereby failing to establish precise boundaries to the construct. The implication is that the range of activities and products may be as broad as the investigator desires (McKercher, 2002).

Contributing to problematic definitional issues is also a measurement problem. The measurement problem has two dimensions. The first dimension is related to the tourist behavior. In many cases tourists choose a mixture of culture and recreation during the same vacation. But most statistics do not track leisure and culturally motivated tourists separately. For example, the tourism statistics only specify as to the purpose of the visit (e.g. vacation, honeymoon, wedding, incentive/award travel, visit friends and family, golf, business and leisure, business only/conference/convention). Consequently, one has to rely on supplementary data in order to estimate the percentage of the tourism related impact that could be culturally driven (Croes \& Severt, 2007). The second dimension is related to the nature of the tourism product itself. Unlike other economic sectors, tourism is a bundle of goods responding to the want of a customer in satisfying his/her needs through the purchase of a variety of services. This leads to a turnover in several economic sectors. Each of these sectors is traced separately and is not aggregated in a number representing total demand or supply of the tourism sector and is therefore not representative of the complete monetary flow.

These issues related to how cultural tourists are defined and accounted for make quantitative estimation cumbersome. It is therefore imperative to clearly establish the parameters of the methodology pursuant to answering the two questions of this study. The current research attempts to segment cultural tourists by considering two dimensions of centrality of trip purpose and depth of experience through adoption of McKercher's (2002) cultural tourist typologies. A growing body of literature claims that some people are more highly motivated to participate in cultural tourism than others. Different tourists have different abilities to engage in cultural and heritage attractions based on an array of factors, which include level of education, income, prior visit, and a host of other factors. McKercher (2002), for example suggests that considering two issues may develop a definition of cultural tourists: the main reason for the trip and level of experiences at the destination. A number of conceptual and empirical studies have attempted to implement this process and explore the typology of cultural tourists.

McKercher (2002) suggests that cultural tourism may be grouped into five segments based on how important culture was in the decision to travel and on the depth of the experience at the destination. He described cultural tourists as serendipitous, purposeful, incidental, causal, or sightseeing. Purposeful cultural tourists were identified as those people who indicated that the main reason to visit a destination was to learn and experience its culture; sightseeing cultural 
tourists indicated less interest in experiencing and more concern with the visiting cultural landmarks; the casual cultural tourists indicated that culture is less important in the decision to visit and do not get deeply involved while at a destination; incidental cultural tourists did not consider culture as the main reason to visit and while at a destination were only superficially involved; and the serendipitous cultural tourists stated that cultural tourism played little or no role in their decision to visit but once at a destination had a deep experience.

And yet, international bodies, such as the World Tourism Organization, have not provided thus far a disaggregation of tourism motivations that would include culture as defined beyond the traditional characterizations. Typologies continue to be based on conventional approaches, such as vacation, business, visiting friends and relatives, and others. Culture clearly lacks a distinct mention or credible place in the list of tourist motivators. It is therefore difficult to say how much of previous international arrivals are genuinely culturally motivated. It is even more difficult to say which of these "culturally motivated" tourists are defined beyond the conventional definition of cultural tourism. Though cultural tourists are characteristically discrete from leisure tourists, Aruba does not honor that distinction in its statistical analysis of tourists' motivations to visit. This study is pioneer in addressing the explicit distinction that exists between these types of tourists. To honor the distinction, the study applied the cultural tourist typology of McKercher (2000; 2002) to determine the cultural tourist patronizing Aruba.

\section{Methodology}

Aruba is an island that is highly specialized in tourism thereby offering a tourism product portfolio that has employing events, activities and locations that are used as promotional icons for the island. The adverse effect of this specialization for a small island is the transformation that may occur in the social makeup of the destination, which potentially may then disintegrate its local appeal and absorb its cultural authenticity. Hence, the very specialized tourism products that made Aruba a tourist destination could erode the value of those products and could eventually lead to diminishing returns. In order to avoid this from occurring, Aruba is searching for ways to continue the path of increasing returns by repositioning itself. The intense competition in the Caribbean region is compelling this destination to seek market development by increasing the range of cultural attractions that are available to tourists, by increasing tourists' spending, and by stimulating local entrepreneurial activity. As this shift occurs, the island will be looking at new and unique product offerings to enhance the tourist experience. In this shift, the role of cultural entities, events, and new experiences will play a stronger role in attracting visitors to the island. Thus, the island has embarked on a quest for steering its product towards more authentic experiences with the hopes of attracting culturally sensitive tourists.

The typology of cultural tourists and the economic value of each of those types of cultural tourists were tested by the distribution of a survey conducted by the Central Bureau of Statistics of Aruba (CBS). A total of 386 departing international tourists were interviewed at the Reina Beatrix International Airport from Brazil, Canada, Colombia, The Netherlands, Netherlands Antilles, United States, and Venezuela. The CBS combined its monthly generic tourist survey with a special section on cultural tourism. The survey asked questions both in the English and Spanish languages related to the purpose of the visit, to participation in cultural activities, perception regarding the quality of Aruban cultural features, and spending behavior. It was 
important to separate cultural tourists from the rest of the tourist population. The respondents were asked how important the opportunity to learn something about Aruba's culture was in their decision to visit. The next question referred to the depth of experience on the island, followed by a question about their perception of Aruba as a cultural destination. Another question applied the standard definition of "participation" in various activities in which they participated at any time during their stay.

The survey questions were the result of two focus groups that were held in December 2008, in Aruba. The participants in the focus groups represented all walks of cultural life in Aruba, ranging from government agencies, cultural foundations, cultural associations, private entrepreneurs and artists. The focus groups yielded a specific survey design consisting of fifteen questions. The draft survey was discussed with CBS and went through a series of iterations before the final draft. The final section for cultural tourism on the survey consisted of six questions. The CBS administered the survey during the month of July in 2009. The CBS collected the data and codified the results during the month of August. The segments were defined based on break points associated with a scale from "unimportant to the main reason to visit," which was contained in the question, "How important was the opportunity to learn something about Aruba's culture or heritage in your decision to visit Aruba?"

\section{Results}

\section{Cultural Typologies}

Applying the criterion of the purpose of tourists' trip to Aruba clearly narrowed the profile of the cultural tourist visiting the island. It was revealed that only about one in seven tourists indicated that the opportunity to learn something about Aruba's culture or heritage was the main reason to visit. This "specific cultural tourist" accounts for a little more than 124,000 tourists who visited the island in 2008 (15\%), which is still a significant amount of tourists. This is higher than a similar segment identified by McKercher and Du Clos (2002) in Hong Kong (11.8\%), but is similar to the case of Sitges (Spain), where 15\% of the tourists identified culture as their main reason to visit (Binkhorst, 2007).

The results seemed to indicate that the farther tourists traveled, the higher the proportion of tourists who were seeking cultural experiences. Tourists from the Netherlands were more likely to travel to Aruba for cultural reasons than visitors from the USA and Latin America (Venezuela, Colombia, and Brazil in descending order). Tourists from Latin America in general were less likely to visit Aruba for cultural purposes. Only 6\% of the Latin travelers indicated that the main purpose for visiting Aruba was to learn something about Aruba's culture, compared to $11.5 \%$ from the USA and $29.1 \%$ from the Netherlands. Six in ten visitors visited Aruba multiple times. A little over half $(50.4 \%)$ of these visitors are incidental or casual cultural tourists. Incidental and casual cultural tourists were less likely to spend more days than the purposeful cultural tourists. In general, the former spent about 6.35 nights on average on the island. About $58 \%$ of the incidental and casual cultural tourists are younger than 50 years of age, while the purposeful cultural tourists were more likely to be older. The incidental and casual cultural tourists had a higher income $(40.2 \%$ earned more than US\$50,000) than the purposeful cultural tourists $(28.6 \%$ earned more than US\$50,000). 


\section{Participation in Cultural Activities}

Table 1 illustrates that all respondents participated in at least one cultural activity at some time during their stay in Aruba. The degree and scope of participation varied widely among the respondents. While in Aruba, the overwhelming majority of respondents engaged in beach and shopping activities. Gastronomy, visiting historic sites and visiting or participating in cultural events appeared in descending order as the most likely activities that the tourists engaged in during their stay. Thirty six percent of the respondents visited a restaurant with a local cuisine $36 \%$ visited historic sites, and $22 \%$ visited museums, art galleries, festivals and sites of architectural significance. However, the findings suggest a high degree of dispersion of tourists among different cultural attractions, such as gastronomy, historic sites and the traditional cultural attractions.

The purposeful cultural tourists were more likely to visit a restaurant with a local cuisine (about one in two), a little more than one in two were more likely to visit a historic site, and more than eight in ten were likely to visit or participate in some sort of cultural site, activity, or event compared to the casual and incidental tourists. The majority (a little more than two-thirds of the tourists) may be classified as casual or incidental cultural tourists, meaning that cultural tourism played a moderate to small role in the decision to visit the island and while on the island only enjoyed a shallow cultural experience. However, focusing on participation in activities as the determinant for cultural tourists provides little insights in terms of the real motivation to visit Aruba.

Table 1. Sites Visited by Cultural Tourist Typologies

\begin{tabular}{lccccc}
\hline \multicolumn{1}{c}{ Site } & Casual & Incidental & Purposeful & Serendipitous & Sightseeing \\
\hline Beaches & $36 \%$ & $32 \%$ & $16 \%$ & $4 \%$ & $13 \%$ \\
Shopping Malls & $36 \%$ & $30 \%$ & $15 \%$ & $4 \%$ & $14 \%$ \\
Center of Oranjestad & $36 \%$ & $29 \%$ & $16 \%$ & $4 \%$ & $14 \%$ \\
North Coast & $33 \%$ & $18 \%$ & $30 \%$ & $2 \%$ & $18 \%$ \\
San Nicolas & $29 \%$ & $19 \%$ & $29 \%$ & $4 \%$ & $19 \%$ \\
Gastronomy & $36 \%$ & $29 \%$ & $20 \%$ & $5 \%$ & $10 \%$ \\
Rock Formations & $33 \%$ & $13 \%$ & $31 \%$ & $4 \%$ & $20 \%$ \\
Island Tours & $45 \%$ & $22 \%$ & $18 \%$ & $1 \%$ & $13 \%$ \\
National Park (Arikok) & $35 \%$ & $13 \%$ & $29 \%$ & $4 \%$ & $19 \%$ \\
Historical Sites, Franse Pas & $39 \%$ & $19 \%$ & $26 \%$ & $3 \%$ & $14 \%$ \\
Museums, Galleries, & & & & & $10 \%$ \\
Festivals & $30 \%$ & $4 \%$ & $52 \%$ & $3 \%$ &
\end{tabular}

\section{Perception of Aruba as a Cultural Destination}

More than seven in ten visitors perceived Aruba as a destination rich in culture, heritage and history, or as unique in culture (Table 2). Unfortunately, the survey did not provide the opportunity to respondents to specify the attributes that make Aruba's culture unique. The reference of "unique" is a surprising finding for two reasons. First, there was a clear consensus among participants in the focus groups alluded to in the methods that Aruba lacks a unique culture, in sharp contrast to what tourists perceived about Aruba. Second, as Aruba is richly endowed with "traditional" cultural attractions (i.e. museums, galleries or monuments) one could speculate that the respondents were referring to Aruba's culture of the ordinary and everyday. This speculation is based on the current global trend to recognize the realities of cultural change 
in discovering authenticity interacting and engaging with locals. Not surprisingly, the purposeful cultural tourists indicated the strongest position compared to the other segments about Aruba's unique cultural features.

Table 2. Perception of Aruba as a Cultural Destination

\begin{tabular}{lccccc}
\multicolumn{1}{c}{ Perception } & Casual & Incidental & Purposeful & Serendipitous & Sightseeing \\
\hline $\begin{array}{l}\text { Little unique culture, } \\
\text { history or heritage }\end{array}$ & $9 \%$ & $17 \%$ & $0 \%$ & $0 \%$ & $1 \%$ \\
$\begin{array}{l}\text { Rich in culture, history \& } \\
\text { heritage }\end{array}$ & $9 \%$ & $2 \%$ & $13 \%$ & $2 \%$ & $9 \%$ \\
$\begin{array}{l}\text { Some features that are } \\
\text { unique }\end{array}$ & $18 \%$ & $13 \%$ & $3 \%$ & $2 \%$ & $4 \%$
\end{tabular}

Applying McKercher's typology of cultural tourists to the case of Aruba reveals the following (Figure 1).

Figure 1. Cultural Tourist Typology for Aruba

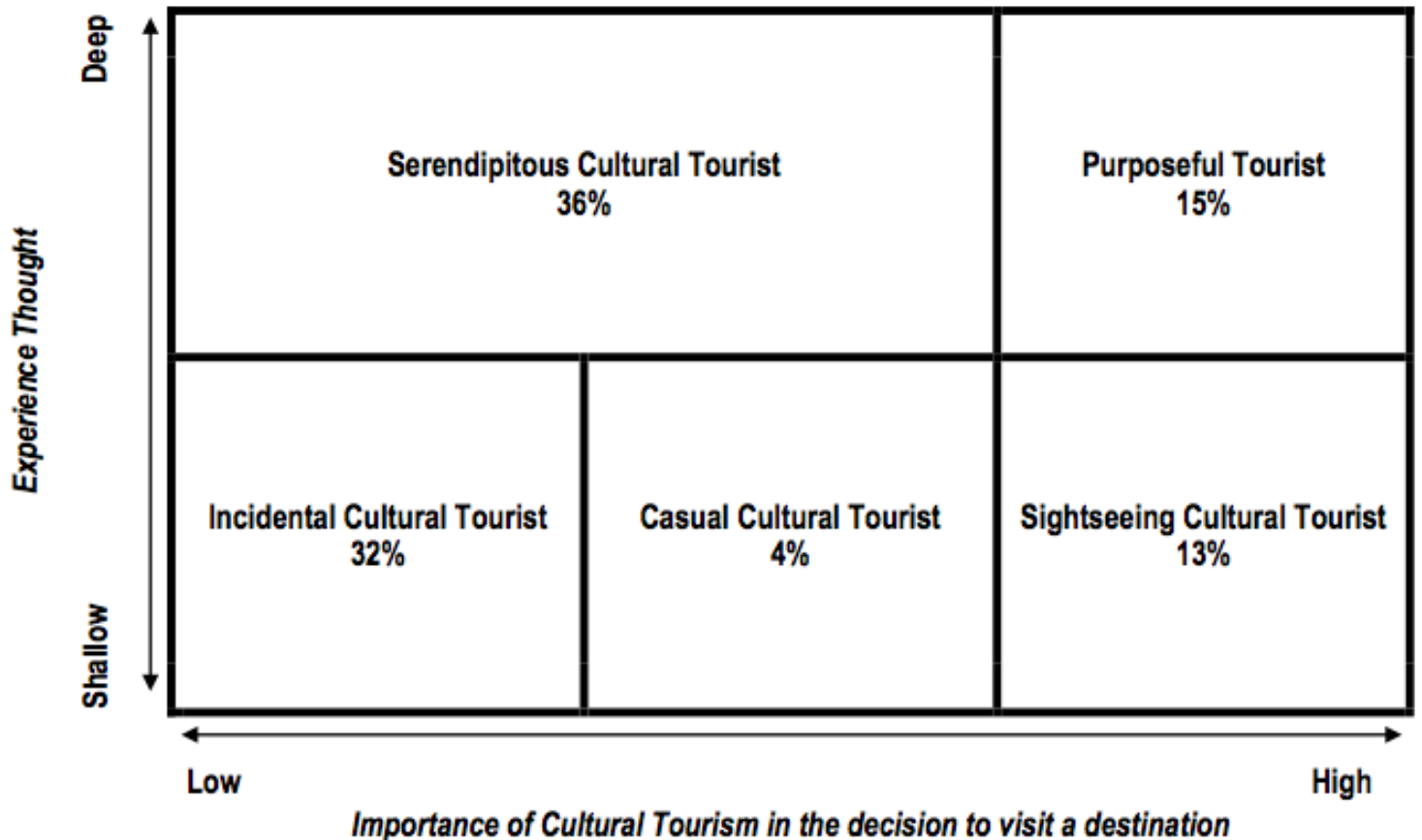

The results thus far indicate that the main purpose for traveling to Aruba was vacationing. Cultural tourism seems to play a marginal role in the decision to visit the island. However, the cultural resource seems to play a greater role during the vacation of the tourist. For example, the serendipitous tourist in Aruba represents 36\%, and while they may be familiar with the local culture, they are surprised of what they experience once they become involved. These tourists were from more culturally distant regions and tended to seek deeper experiences, were younger, stayed about a week, visited Aruba multiple times, and had an income that exceeded $\$ 50,000$. These cultural tourists constitute a little more than half of the tourists and portrayed a distinct profile in terms of tastes and preferences. Finally, the specific cultural tourists were likely to 
find Aruba's culture unique and appeared to define culture more in terms of everyday life and the ordinary than the "traditional" cultural attractions.

The next step in the research process was to assess the economic impact of consumption from the cultural tourist typologies. The study applied an Input-Output (I-O) model in order to determine the economic impact of cultural tourism in Aruba. The I-O tables used in this study were derived from Steeg (2009). The spending behavior of the respondents was inferred from the survey. The last question of the survey specifically referred to spending on cultural or historical activities, such as historical sites, cultural events, arts, crafts, photography, books, music, educational materials, National Park Arikok, entertainment (movies, museums, galleries, sightseeing tours), and other cultural related activities. Spending by these cultural tourists increases local production (and incomes). Assuming there is idle capacity and prices do not respond to increased demand, the final increase is bigger than the initial increase (the multiplier effect). The distribution of direct, indirect, and induced expenses for the model of economic impact was applied to Aruba as follows: the direct expenses, the indirect expenses, the induced effects that are created by direct and indirect expenditure.

\section{Consumption and production of cultural artifacts and services}

The findings reveal two interesting patterns about the tourists visiting Aruba. The first refers to the extent of participation in cultural activities while in Aruba. Respondents indicated that they have participated in at least one cultural activity. These activities range from entertainment to arts, crafts, photography, books, music, education, and historical sites. The outcome of that participation equals US\$23.14 million in direct spending in the purchase of cultural goods and services (See Table 3). This is equivalent to $2 \%$ of the total international receipts in 2008.

The second refers to the spending behavior. Cultural tourists to Aruba spent on average per person per trip an amount of US\$30.81 on different products and services. The purposeful cultural tourist was the highest spender with US\$66.61, followed by the casual (US\$32.95), sightseeing (US\$30.81), serendipitous (US\$19.12), and incidental (US\$14.62). Considering activities as the determinant for defining the cultural tourists, as the WTO seems to suggest, would indicate that basically all tourists visiting Aruba would correspond to some extent to one of the cultural segments as indicated by McKercher.

Table 3. Direct, Indirect and Induced Impact for all Cultural Tourists

\begin{tabular}{llllr}
\hline Industry & Direct & Indirect & Induced & \multicolumn{1}{l}{ Total } \\
\hline Agriculture, hunting, forestry, fishing & $\$ 0$ & $\$ 129,525$ & $\$ 62,294$ & $\$ 191,819$ \\
Mining and quarrying & $\$ 0$ & $\$ 46,156$ & $\$ 103$ & $\$ 46,259$ \\
$\begin{array}{l}\text { Manufacturing } \\
\text { Electricity, gas, refined petroleum }\end{array}$ & $\$ 0$ & $\$ 830,389$ & $\$ 737,490$ & $\$ 1,567,879$ \\
products & $\$ 0$ & & & \\
Construction & $\$ 4,625,875$ & $\$ 502,531$ & $\$ 231,902$ & $\$ 5,360,308$ \\
Wholesale and retail trade & $\$ 9,761,957$ & $\$ 1,799,350$ & $\$ 1,683,451$ & $\$ 13,244,759$ \\
Hotels & $\$ 4,358,398$ & $\$ 78,120$ & $\$ 42,020$ & $\$ 4,478,538$ \\
Restaurants & $\$ 0$ & $\$ 106,265$ & $\$ 667,429$ & $\$ 773,694$ \\
Transport, storage and communications & $\$ 0$ & $\$ 899,818$ & $\$ 1,029,663$ & $\$ 1,929,482$ \\
Financial intermediaries & $\$ 0$ & $\$ 1,625,417$ & $\$ 1,090,605$ & $\$ 2,716,022$ \\
Other business activities & $\$ 0$ & $\$ 1,636,553$ & $\$ 3,624,773$ & $\$ 5,261,326$
\end{tabular}




\begin{tabular}{llllr} 
Public administration/Social Security & $\$ 4,393,574$ & $\$ 155,282$ & $\$ 214,617$ & $\$ 4,763,527$ \\
Education & $\$ 0$ & $\$ 31,283$ & $\$ 92,936$ & $\$ 124,219$ \\
Health and social work & $\$ 0$ & $\$ 13,230$ & $\$ 125,144$ & $\$ 138,374$ \\
Other community social service activities & $\$ 0$ & $\$ 106,855$ & $\$ 1,127,039$ & $\$ 1,233,894$ \\
Households & $\$ 0$ & $\$ 0$ & $\$ 15,160,286$ & $\$ 15,160,286$ \\
\hline Total & $\$ 23,139,804$ & $\$ 8,931,821$ & $\$ 27,362,531$ & $\$ 59,434,211$ \\
\hline
\end{tabular}

*Calculation based on Steeg (2009)

Total Economic Contribution of Consumption and Production of Cultural Artifacts and Services The contribution of the cultural tourism segment to the economy of the island includes both the direct effects of economic activities in tourism related industries as well as the indirect and induced (multiplier) effects that ripple through the local economy. Therefore, the roughly US $\$ 23.1$ million spent by the cultural tourists in the tourism economy generated an additional US\$8,931,821 in indirect economic impacts for the island. This is equal to a multiplier of 1.36. The induced effects, on the other hand, generated an additional US $\$ 27,362,531$ for a multiplier of 2.19. The induced effects were significantly higher than the indirect effects, meaning that the impact is greater in the field of salaries and benefits than in sales for other businesses. The total economic contribution of the cultural tourism segments through the purchase of cultural goods and services amounted to US\$59,434,211.

The sales patterns also provide an indication of how widely spread cultural tourism is throughout the economy. Multiplier effects denote the linkages in the local economy. Linkages to retail, food and beverages, entertainment and recreation, professional and administrative services, finance and insurance, health and social services, and government have effects throughout the local economy, according to the findings of this study. Both of the multipliers were above one, translating a portion of sales into household income.

\section{Consumption of the Purposeful Cultural Tourist}

If the definition of cultural tourists is more narrowly measured, for instance, through the purpose of their visits, and if all the expenditures of this segment of tourists are taken into account, the total number becomes significant. Fifteen percent of all respondents stated that culture was the main purpose for their visit to Aruba. This is equivalent to an amount of over 124,000 tourists in 2008 arrivals. The total direct spending including all expenditures, such as accommodation, transportation, restaurants, shopping, entertainment, cultural goods and services, etc. was estimated at US\$245.7 million, while its total economic contribution was estimated at US\$623 million. The multiplier was 2.52 .

The study compared this segment of cultural tourists to the leisure tourist (85\%) visiting Aruba. By estimating the expenditure for each segment separately we were able to simulate the economic impact for each group. The direct spending of the leisure segment was estimated at US $\$ 1,156$ million and it generated a total economic contribution of US $\$ 2,965$, equivalent to a multiplier of 2.5 (See Table 4). Tourists (both cultural and leisure) spent more than US\$41 million on cultural activities and goods, which equals to $3 \%$ of the total tourism receipts.

Table 4. Spending by Cultural and Leisure Tourist

\begin{tabular}{lcccc}
\hline Categories & \multicolumn{2}{c}{ Cultural Tourist } & \multicolumn{2}{c}{ Leisure Tourist } \\
\hline Cultural Spending & $\$ 12,418,834$ & $5 \%$ & $\$ 29,232,052$ & $3 \%$
\end{tabular}




\begin{tabular}{lcccc} 
Transportation & $\$ 18,846,568$ & $8 \%$ & $\$ 63,644,741$ & $6 \%$ \\
Shopping & $\$ 29,334,878$ & $12 \%$ & $\$ 134,854,530$ & $12 \%$ \\
Food & $\$ 73,303,282$ & $30 \%$ & $\$ 263,511,946$ & $23 \%$ \\
Other Spending & $\$ 14,461,000$ & $6 \%$ & $\$ 94,379,687$ & $8 \%$ \\
Accommodation & $\$ 56,025,237$ & $23 \%$ & $\$ 346,330,044$ & $30 \%$ \\
Entertainment & $\$ 23,876,476$ & $10 \%$ & $\$ 122,531,884$ & $11 \%$ \\
Casino & $\$ 17,398,828$ & $7 \%$ & $\$ 101,850,012$ & $9 \%$ \\
\hline Total & $\$ 245,665,103$ & $100 \%$ & $\$ 1,156,334,896$ & $100 \%$ \\
\hline
\end{tabular}

1= Historical Sites, Cultural Events Arts and Crafts, Photo Books, Music, Education, Arikok, Cultural Entertainment;2= Taxi, Car Rental, Other Transportation; 3= All shopping excluding cultural related items; $4=$ Food, Beverage, Groceries; $5=$ Hotel or other lodging; $6=$ All entertainment excluding cultural events

The study also included a t test for all spending categories per person per trip in order to test for significant differences in spending behavior. The study found a significant difference in cultural spending $(t=5.227)$, transportation $(t=4.297)$, and food (4.135). The results indicate that cultural tourists spend more on cultural activities and goods, they seem to enjoy eating out and they seem to be more 'foot loose' around the island - their mobility affording greater opportunity for a full lifestyle experience than the leisure tourist. In addition, the cultural tourist tends to spend $16 \%$ more while on the island (US\$1,981) compared to the leisure tourist (US\$1,645). This result provides support regarding the claim that is made in literature that the cultural tourist is more likely to spend more money than a leisure tourist.

\section{Conclusions}

McKercher's typology seems limited in its application to a small island destination, such as Aruba. The typology is imputed through the identification of a cultural tourist when considering the tourists' behavior through their chosen cultural activities when at a destination. These activities may assist in the determination of the role that culture may play in the destination choice process of a tourist. However, the typology does not allow for one to conclude whether the tourist entertain a self-perception as cultural tourists. In other words, while the tourist may be involved with all kinds of cultural activities while on vacation, the tourist may not consider himself as a cultural tourist. As McKercher's typology did not require the asking of the tourists directly about the purpose of their visit to a destination; it was revealed that by not asking the purpose of their trip it could cloud the ability to quantify the economic significance of this segment for a small island destination.

In addition, the typology seems to consider only activities that are heritage based. In this sense, culture may be viewed as preserving something related to history and not referencing the dynamic pressures for change and permutations in everyday cultural activities and lifestyles. In the case of Aruba, the overarching theme in the discussion with local stakeholders during the focus groups was their keen desire to identify what is culturally distinguishable from other small island destinations. The local identity of distinguishable cultural traits from the stakeholders seemed in flux thereby affecting a clear understanding of what is authentic Aruban. The reason seems to be that culture is a dynamic concept imbued with constant negotiations within a constantly changing context. The role of the past in defining the self as an imposed interpretation 
of what is authentic Aruban style in some a priori form seems to collide with the relevance of inclusiveness and the everyday life.

The study clearly indicates that there may be potential for the production of cultural tourism attractions and activities in offering tourists access to the everyday life. There is where the heart of the curiosity of the tourist seems at its peak. If this were to be the case then it seems that cultural tourists could indeed be the next frontier for Aruba. Future research should more closely investigate the meaning and economic value of the everyday life in the context of a small island destination.

\section{REFERENCES}

Binkhorst, E. (2007). "Creativity in Tourism Experiences, the Case of Sitges”. In Richards, G. and Wilson, J. (2007),Tourism, Creativity and Development, Oxon: Routledge.

Bendixen, P. (1997). Cultural Tourism-Economic Success at the Expense of Culture. International Journal of Cultural Policy 4(1), 21-46.

Brau, R, Lanza, A. \& Pigliaru, F. (2003). How Fast are the Tourist Countries Growing? The Cross- Country Evidence, FEEM Working Paper Series, No.85-2003.

Briguglio, L., Archer, B., Jafari, J. and Wall, G. (1996). Sustainable Tourism in Islands and Small States: Issues and Policies. London: Pinter.

Croes, R. (2006). A paradigm shift to a new strategy for small island economies: embracing demand side economics for value enhancement and long terms economic stability. Tourism Management, 27, 453-465.

Croes, R. and Severt, D. (2007). Evaluating short-term tourism economic effects in confined economies: conceptual and empirical considerations. Tourism Economics, 13, 289-307.

Croes, R. (2011). Measuring and explaining competitiveness in the context of small island destinations. Journal of Travel Research 50(4), 431-442.

McKercher, B. (2002). Towards a classification of cultural tourists, International Journal of Tourism Research, 4, 29-38.

McKercher, B. \& du Cros, H. (2002). Cultural Tourism: The Partnership between Tourism and Cultural Heritage Management. New York: Hayworth Hospitality Press.

Pizam, A. and Croes, R. (2007). Tourism through times: from Agrarian societies to innovationbased economies, Asian Journal of Tourism and Hospitality Research, 1(1), 3-24.

Richards, G. (1996). Production and Consumption of European Cultural Tourism. Annals of Tourism Research, 23(2), 261-283. 
Richards, G. (2001). Cultural Attractions and European Tourism. Wallingford: CABI.

Richards, G. and Wilson, J. (eds) (2007). Tourism, Creativity and Development. London: Routledge.

Richards, G. (ed) (2007). Cultural Tourism, Global and Local Perspectives. New York: The Haworth Hospitality Press.

Romer, P. (1994). The Origins of Endogenous Growth. The Journal of Economic Perspectives, 8(1), 3-22.

Smith, M. and Robinson, M.(eds) (2006). Cultural Tourism in a Changing World, Politics, Participation and (Re) presentation. Clevedon: Channel View Publications.

Smith, M. (ed.) (2007). Tourism, Culture \& Regeneration. Wallingford: CAB International.

Snowball, J. (2008). Measuring the Value of Culture: Methods and Examples in Cultural Economics. Berlin: Springer.

Steeg, A. van de (2009). Accounting for Tourism, The Tourism Satellite Account in Perspective. The Hague: University of Groningen.

World Tourism Organization (2005). City Tourism \& Culture: The European experience. A Report of the World Organization and of the Research Group of the European Travel Commission. Madrid: WTO. 